\title{
German and Russian Irradiated Reactor Pressure Vessel Steels from PAS Point of View
}

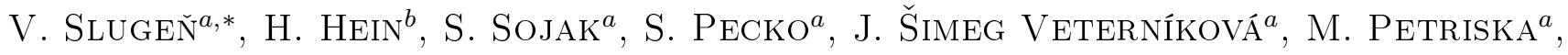 \\ V. SABelová ${ }^{a}$, I. BARTOŠOVÁ ${ }^{a}$ AND M. StaChO ${ }^{a}$ \\ ${ }^{a}$ Institute of Nuclear and Physical Engineering, Slovak University of Technology \\ Ilkovičova 3, 81219 Bratislava, Slovakia \\ ${ }^{b}$ AREVA NP GmbH, Paul Gossen Str. 100, 91001 Erlangen, Germany
}

\begin{abstract}
This paper presents a comparison of commercially used German and Russian reactor pressure vessel steels from the positron annihilation spectroscopy point of view, having in mind knowledge obtained also from other techniques from the last decades. The second generation of Russian reactor pressure vessel steels seems to be fully comparable with German steels and their quality allows prolongation of NPP operating lifetime over projected 40 years. The embrittlement of $\mathrm{CrMoV}$ steels is very low due to the dynamic recovery of radiation-induced defects at reactor operating temperatures. Positron annihilation spectroscopy techniques can be effectively applied for evaluation of microstructural changes caused by extreme external loads by proton implantation, with aim to simulate irradiation and for the evaluation of the effectiveness of post-irradiation thermal treatments. We used our actual and previous results, collected during last 20 years from measurements of different reactor pressure vessel steels in "as received", irradiated and post-irradiation annealed state and compare them with the aim to contribute to general knowledge based on experimental positron annihilation spectroscopy data.
\end{abstract}

DOI: $10.12693 /$ APhysPolA.125.726

PACS: 28.41.Qb, 61.72.-y, 78.70.Bj

\section{Introductions}

Degradation of the reactor pressure vessel (RPV) steel depends on many factors as thermal and radiation treatment, chemical composition, manufacturing conditions, ageing, microstructure of the RPV material, operational history, etc. [1]. In this paper we focus on the comparison of German and Russian RPV steels from the positron annihilation spectroscopy (PAS) point of view, having in mind knowledge obtained also from other techniques from the past.

\section{Specimens}

Our PAS studies were focused on Russian VVER-440 steels for more than last 15 years. Results were reported in detail in book Safety of VVER-440 Reactors [2]. The chemical composition of the studied German steels is listed in Table. These steels have been comprehensively studied in the research programs CARISMA and CARINA [3]. All specimens belong to commercial reactor pressure vessel steels and vary mostly in the content of $\mathrm{Cu}, \mathrm{P}$ and Ni. All of the studied steels come from pressurized water reactors of different designs - western and eastern (Soviet).

Neutron irradiated specimens (Table) of western CARINA/CARISMA reactor steels were delivered to our Institute in September 2012. Due to the radioactivity of mentioned neutron irradiated specimen, the special safety requirements for transport of specimens from

*corresponding author; e-mail: vladimir.slugen@stuba.sk
TABLE

Chemical composition of irradiated German RPV steel specimens selected for PAS studies.

\begin{tabular}{c|c|c}
\hline \hline Material & P16 WM & P370 WM \\
\hline \multicolumn{2}{|c}{ Manufactured by arc welding } \\
\hline place of analysis & \multicolumn{2}{|c}{ Mean values [\%] } \\
\hline $\mathrm{C}$ & 0.05 & 0.08 \\
$\mathrm{Si}$ & 0.15 & 0.15 \\
$\mathrm{Mn}$ & 1.14 & 1.14 \\
$\mathrm{P}$ & 0.012 & 0.015 \\
$\mathrm{~S}$ & 0.007 & 0.013 \\
$\mathrm{Cr}$ & 0.07 & 0.74 \\
$\mathrm{Mo}$ & 0.46 & 0.60 \\
$\mathrm{Ni}$ & 1.69 & 1.11 \\
$\mathrm{Cu}$ & 0.08 & 0.22 \\
$\mathrm{~V}$ & 0.004 & 0.010 \\
$\mathrm{Co}$ & 0.024 & - \\
$\mathrm{Al}$ & 0.022 & 0.013 \\
$\mathrm{Sn}$ & - & 0.013 \\
$\mathrm{As}$ & - & 0.014
\end{tabular}

AREVA NP GmbH Erlangen (Germany) to the Institute of Nuclear and Physical Engineering, FEI STU Bratislava (Slovakia) were needed in form of licensed transport using marked barrel to avoid any influence of activated specimens on outer environment.

Measurement of positron lifetime was realized in air conditioned unit in order to sustain stability and efficiency of measuring equipment. Measurements of neutron irradiated specimens can be performed only with 
three-detector setup. As the source of positrons in positron annihilation lifetime measurements (PALS) was used ${ }^{22} \mathrm{Na}$ in solution of $\mathrm{NaCl}$ instilled between $7 \mu \mathrm{m}$ kapton foils. Source contribution after reference fit of pure silicon was at level of about $24 \%$. This includes the annihilation in source, kapton foils and "in-flight" annihilation. Intensity of annihilation in air (in-flight) was at level of $1-2.5 \%$. Positron annihilation lifetime spectra were analyzed using software LT version 9 [4]. The software was created in DELPHI development environment and is fully compatible with Windows operating system.

\section{PAS results from irradiated German RPV steels}

The CARISMA materials were irradiated in a German test reactor, the VAK (Versuchsatomkraftwerk Kahl), in the $1980 \mathrm{~s}$ in the frame of a dedicated irradiation program in order to make provisions for future changes of RPV safety requirements and possible long term operation (LTO) measures. The irradiation temperature was mainly in a range between 280 and $290^{\circ} \mathrm{C}$. All 3 specimens P370 WM (two irradiated D-77 and D-161, as well as one non irradiated CD159) are from the same bulk but cut at different positions. The same is valid also for both P16 WM specimens (S103 and GS67). Unfortunately, there was no specimen from non-irradiated P16 WM material.

Mean positron lifetime (MLT) includes positron annihilation in air and therefore some variables can be introduced into the data evaluation. Therefore, average lifetime was calculated from measured data, including only annihilation in components $\tau_{1}$ and $\tau_{2}$.

It was proved that performed irradiation treatment caused increase of positron lifetimes in studied specimens. In the case of both P370SG specimens, the increase of $\tau_{\text {avg }}$ parameter was from 142 ps to $147 \mathrm{ps}$ and $157 \mathrm{ps}$, respectively (Fig. 1). Results achieved for the average lifetime were at level of about 172 ps for the both P16SG specimens.

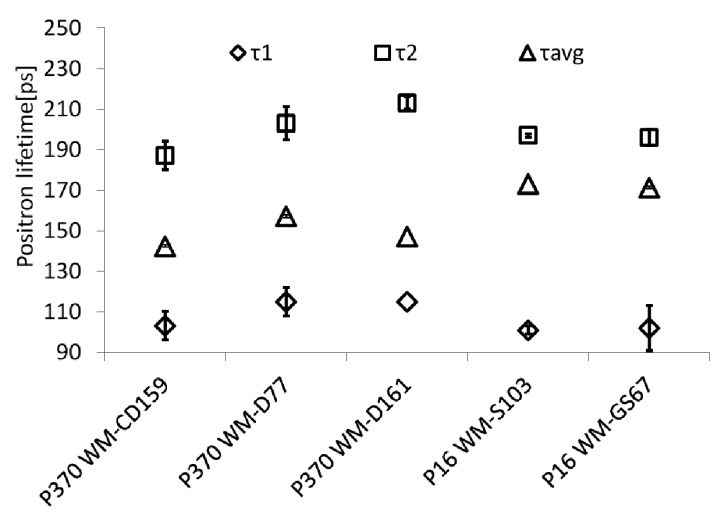

Fig. 1. Positron lifetimes $\tau_{1}, \tau_{2}$ and $\tau_{\text {avg. }}$.

The positron lifetime in defects, characterized via parameters $\tau_{2}$ and $I_{2}$, are shown in Fig. 1 and Fig. 2. In the case of P16WM steels, the lifetime $\tau_{2}$ is at the level of about $195 \mathrm{ps}$. It shows the presence of the small vacancy clusters with the size of about $1-2$ vacancies. In the case of the steel P370WM, the lifetimes in defects are higher and with values of about 210 ps. It could indicate vacancy clusters of $2-3$ vacancies [5]. For the first component $\tau_{1}$ there are the positron lifetimes from about $100-115$ ps and this could be caused by the superposition of the reduced bulk component and another component which is expressed by a bit higher values of positron lifetimes containing some partial dislocations (shallow traps).

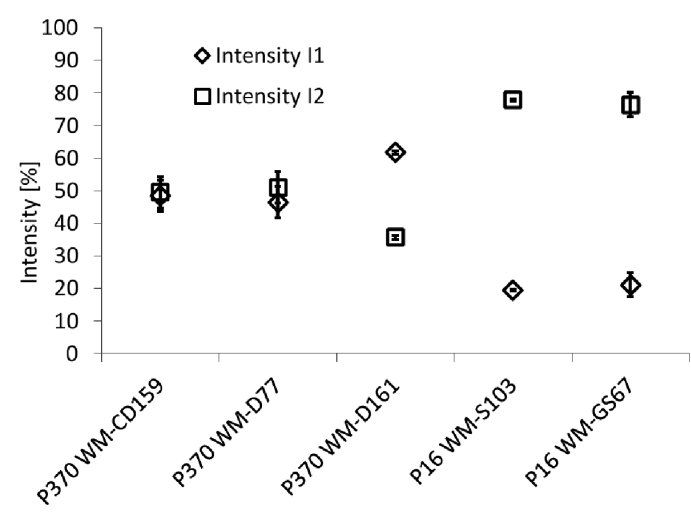

Fig. 2. Intensities of positron lifetimes $I_{1}$ and $I_{2}$.

If we consider the data from the plot of intensities (Fig. 2) assigned to the first lifetime component $\left(I_{1}\right)$ and defect structures $\left(I_{2}\right)$ we can see that the intensities of annihilation components in defects in the case of high $\mathrm{Ni}(1.69 \mathrm{wt} \%)$, low $\mathrm{Cr} 0.07 \mathrm{wt} \%$ and low $\mathrm{Cu}(0.08 \mathrm{wt} \%)$ P16 WM steels are at a level of about $75 \%$. This means that the smaller defects (dislocation lines and mono- or di-vacancies) in relatively high amount are more homogeneously distributed in the microstructure of P16 WM. In the case of steels with relatively low $\mathrm{Ni}$ (1.11 wt\%) but high $\mathrm{Cr}(0.74 \mathrm{wt} \%)$ and $\mathrm{Cu}(0.22 \mathrm{wt} \%) \mathrm{P} 370 \mathrm{WM}$, the intensities of defects are much lower but the lifetimes in defects are higher. So the defects are bigger (2-3 vacancies) and not so homogeneously distributed. This can be due to $\mathrm{Cu}$ precipitation after irradiation. According to previous works $[1,6-10]$ it seems to be generally accepted that (even in those Western types of RPV steels containing more than $0.1 \mathrm{wt} \%$ of $\mathrm{Cu}$ ) $\mathrm{Cu}$-rich and, depending on $\mathrm{P}$ content, $\mathrm{P}$-rich precipitates play a dominant role in radiation induced embrittlement.

For the comparison of irradiated and as-received (non-irradiated) specimens we have got only P370 WM material. Unfortunately, there were only irradiated specimens from P16 WM and the non-irradiated material absented completely. So, the direct comparison can be performed only on P370 WM - irradiated D77, D161 and the non-irradiated CD159, which were identical in chemical composition and cut from one bulk. Unfortunately, due to probably long term storage at different positions as well as perhaps not ideal material homogeneities, some 
small microstructural differences were registered (Fig. 1 and Fig. 2). Nevertheless, the differences of both irradiated specimens from the same materials are in frame of the error bars (Fig. 1 and Fig. 2).

\section{Conclusion}

Based on our PAS results we stated that no large voids or vacancy cluster were formed due to irradiation in Russian as well as in German RPV steels. The performed neutron treatment of RPV steels caused at both studied materials an increased trend of defects concentration with increased neutron doses.

According to the comparison of German and Russian commercially used reactor RPV steels, it seems that Russian RPV steels contain more defects in "as received" state (delivered generally from higher MLT) [2]. If we focus our attention on so-called "small-defect component" - $\tau_{2}$ value, its intensity is higher in the case of Russian-RPV steels $(67 \%$ in the case of base metal and $57 \%$ in the case of weld) [2] in comparison to German steels, where these intensities are significantly lower (maximal value $49 \%$ in the case of weld P370WM). On the other hand, these defects are a little bit larger (about 200 ps) which implies higher concentration of di-vacancies in German steels. In the case of Russian steels we registered higher concentration of dislocations and mono-vacancies.

PAS results from irradiated German and Russian steels confirmed that no large voids or vacancy clusters were formed. This fact can be interpreted in the conclusion that vacancy type defects bear hardly any responsibil- ity for radiation-induced hardening and embrittlement $[2,11]$. This mechanism does not limit lifetime of reactor pressure vessel and does not affect significantly the long-term operation of nuclear power plants from safety point of view.

\section{References}

[1] L.M. Davies, Int. J. Press. Vess. Piping 76, 163 (1999).

[2] V. Slugen, Safety of VVER Reactors, Springer, London 2011.

[3] H. Hein, E. Keim, H. Schnabel, T. Seibert, A. Gundermann, J. ASTM Int. 6, JAI101962 (2009).

[4] J. Kansy, LT for Windows, Version 9.0, Silesian University, Poland 2007.

[5] P. Hautojärvi, L. Pöllönen, A. Vehanen, J. YliKauppila, J. Nucl. Mater. 114, 250 (1983).

[6] N.N. Alekseenko, A. Amaev, I. Gorynin, V.A. Nikolaev, ANS Russ. Mater. Monogr. Series 2, Springer, London 1997.

[7] M. Ghoniem, F.H. Hammad, Int. J. Press. Vess. Piping 74, 189 (1997).

[8] J. Kohopaa, R. Ahlstrand, Int. J. Press. Vess. Piping 76, 575 (2000).

[9] L. Debarberis, U. von Estorff, S. Crutzen, M. Beers, H. Stamm, M.I. de Vries, G.L. Tjoa, Nucl. Eng. Des. 195, 217 (2000).

[10] J. Koutsky, J. Kocik, Radiation Damage of Structural Materials, Academia, Prague 1994.

[11] V. Slugen, H. Hein, S. Sojak, J. Simeg Veternikova, M. Petriska, V. Sabelova, M. Pavuk, R. Hinca, M. Stacho, J. Nucl. Mater. 442, 499 (2013). 